\title{
INFANTILE HEMANGIOENDOTHELIOMA OF THE SUBMANDIBULAR GLAND - A CASE REPORT
}

Sunethri Padma, Bheeshma, I. Sreelakshmi, S. S. S. Quadri. P. Jijiya Bai

1. Assistant Professor, Department of Pathology, Gandhi Medical College. Secunderabad, Andhrapradesh,

2. Associate Professor, Department of Pathology, Gandhi Medical College. Secunderabad, Andhrapradesh,

3. Assistant Professor, Department of Pathology, Gandhi Medical College. Secunderabad, Andhrapradesh,

4. Assistant Professor, Department of Pathology, Gandhi Medical College. Secunderabad, Andhrapradesh,

5. Professor, Department of Pathology, Gandhi Medical College. Secunderabad, Andhrapradesh,

\section{CORRESPONDING AUTHOR}

\section{Dr. Sunethri Padma}

Department of Pathology,

Gandhi Medical College,

Secunderabad, Andhrapradesh,

E-mail: sunethripadma@yahoo.co.in,

Ph: 00919885830564.

\begin{abstract}
ABSRACT: Infantile hemangioendothelioma is a benign neoplasm of the salivary gland .The lesion is comprised of round to oval cells with few spindle cells arranged in vascular channels .We present a case of 15 month old female child with swelling in the submandibular region . Radiologically the lesion was found to be of submandibular gland origin .Fine needle aspiration yielded only blood elements .Excision was done and histology showed morphology of Infantile hemangioendothelioma. Infantile hemangioendothelioma of salivary glands was reported in parotid gland, but its occurrence in the submandibular gland has not been reported till now to the best of our knowledge.
\end{abstract}

KEY WORDS: Submandibular gland, Infantile hemangioendothelioma, benign neoplasm

Salivary gland neoplasms are rare. They constitute to $3 \%$ of the head and neck tumors(1).The incidence of neoplasms is high in parotid gland when compared to the Submandibular salivary gland(2).In children congenital malformations of the salivary glands are more common than neoplasms. Most of the benign neoplasms in this age group are of vascular origin. These lesions regress progressively and hence surgical intervention should be selective and appropriate.

CLINICAL HISTORY: A 15 months old female child presented to the department of paediatric surgery with a swelling in the submandibular region on right side. This swelling was informed to be noticed one month back .It was gradually increasing in size and was not associated with pain .There was no history of trauma. Clinical examination revealed a swelling of about $3 \times 3 \mathrm{~cm}$,nontender, well defined margins and skin over the swelling was normal .The child was then sent to radiology department for X-ray and ultrasonography. Both confirmed the lesion to be of Submandibular gland origin .Ultrasound showed that lesion was solid with high vascularity and a provisional diagnosis of neoplasm was given. Then the swelling was subjected to FNAC. But repeated aspirations yielded only blood elements. The subject was then observed for another one month and the swelling was found to increase in size. Then excision was done and specimen was sent to the laboratory for histopathological examination. Clinical photograph of the case was not available as the lesion was already excised before we could diagnose it. 
PATHOLOGICAL EXAMINATION: Gross findings: We received a single gray brown soft tissue mass measuring $2 \times 2 \times 1 \mathrm{~cm}$.Cut section showed solid gray brown tissue with areas of hemorrhage.

Tissue bits were taken and subjected to routine processing .Sections were taken for routine H\&E staining and Immunohistochemistry

MICROSCOPY: Section studied revealed normal salivary gland tissue along with a partially encapsulated lesion comprised of round to oval cells in solid sheets at places surrounding vascular spaces with inconspicuous lumina. These cells are more or less uniform with scant to moderate amount of cytoplasm and vesicular nucleus. At places the acini and ducts were seen entrapped within the lesion. No evidence of mitotic activity or atypia.

DISCUSSION: Salivary gland neoplasms are uncommon in children. The spectrum of tumors of salivary gland in infancy and child hood are distinctive(3).The incidence of benign and malignant neoplasms in children is debatable(4).However most of the studies have shown that malignant tumors are rare in children when compared to benign(5).In children parotid gland is mostly involved(6). Pleomorphic adenoma is the most common neoplasm in children and adolescents(7).

Vascular lesions of salivary gland are frequently encountered in children. Clinically these entities present as painless masses .In this age group vascular neoplasms have to be differentiated from vascular malformations (8).Some authors have subclassified Hemangiomas as Usual hemangiomas and juvenile or capillary hemangiomas by some authors (9).These are more common in females(3).Infantile hemangioendothelioma is usually a benign vascular lesion but occurrence of malignant sarcomas have been reported $(7,8,9)$.Some authors have labelled capillary hemangioma in infants as Infantile hemangioendothelioma .Other synonyms of this lesion are cellular hemangioma of infancy, straw berry nevus, Juvenile hemangioma and Immature capillary hemangioma. This lesion can occur in any organ but commonest sites are skin, and soft tissue. It can also present as abdominal mass or liver mass.

Hemangiomas constitute $0.4 \%$ of the salivary glands tumors and they are more common in parotid gland. The occurrence of Infantile hemangioendothelioma in submandibular gland is extremely rare and this makes our case more remarkable .Grossly these lesions can be solitary or multicentric .Histopathological sections show capillary like small proliferating vessels in major portion of the lesion .The lining cells are plump ,occasionally epithelioid like with pericytes .Occasionally mitotic figures can be noted along with hypovascular stroma, central necrosis and calcification.Perineural invasion is rare but when present does not denote the malignant behaviour of the tumor. Differential diagnosis includes capillary hemangioma, Infantile Angiosarcoma and rarely angiosarcoma when mitotic figures are high.

FNAC and CT scan were found to have immense utility in diagnosis of these lesions(13).However in our case FNAC yielded only blood. Reticulin stain is also useful in differentiating these lesions from other members. Immunohistochemistry is of great use in the diagnosis of these tumors. Vascular markers like factor vIII and CD 34 are strongly positive .A single endothelial marker, GLUT-1, is now available. This immunophenotype is present in all cases of infantile haemangioma at every stage and is negative in other tumors(14). Recent studies have shown that Prox1 transcription factor acts as a marker to differentiate hemangioendotheliomas. 
CONCLUSION: Infantile hemangioendothelioma of Submandibular gland is extremely rare and has to be differentiated from other similar vascular lesions. These neoplasms are known to regress over a period of time .Hence surgical management in these cases should be precise .A definite diagnosis and appropriate management is mandatory while treating a case of salivary gland tumor in children.

\section{REFERENCES:}

1. Becerrel-Ramfrez,perla Bernice etal Histology of Submandibular Gland Tumors,10 years Experience Acta Otornolaryngol Esp,2011;62;432-5,vol 62

2. Adeyemo WL et al Tumours of the Submandibular salivary gland: a clinicopathologic review of cases over a 17-year period.. West Indian med. j. vol.58 no.4 Mona Sept. 2009

3. Arch Otolaryngol Head Neck Surg. 1988 Aug;114(8):898-906

4. Craver RD,Fonseca etal,Pediatric epithelial salivary gland tumours: spectrum of histologies and cytogenetics at a childrens hospital Pediatr dev Pathol.2010 sepoct;13(50:348-53.Epub 2010 Jan 7

5. Otolaryngol Pol. 2012 Mar-Apr;66(2):152-4

6. Prezewonzy T,Stodulski D Major salivary gland disorders in children and adolescents Otolaryngol Pol 2011 Seo-Oct;65(5):350-6

7. J Med Case Rep. 2012 Sep 11;6(1):287,

8. Enjolras O, Soupre V, Picard A. Classification of superficial vascular anomalies 2010 Apr;39(4):457-64. Epub 2010 Mar.

9. Ann Diagn Pathol. 2002 Dec;6(6):339-4

10. Zenge JP,Fenton L,Lovell MA,Grover TR.Case report: Infantile hemangioendothelioma.Curr Opin pediatr 2002;14:99-102

11. Mortele KJ, Vanzielegham B, etal.Solitary hepatic infantile hemangioendothelioma: dynamic gadoliniumenhanced MR imaging findings.Eur Radiol 2002;12:862-865

12. Ingram JD,Yerushalmi etal Hepatoblastoma in a neonate: a hypervascular presentation mimicking hemangioendothelioma. Pediatr radiol 2000;30:794-797

13. Chua DY, KO C etal. Submandibular mass excision in an Asian population a 10 year review Ann Acad Med Singapore.2010nJan;39(1):33-7

14. Enjolras O, Soupre V, Picard A [Classification of superficial vascular anomalies Presse Med. 2010 Apr; 39(4):457-64. Epub 2

15. Miettinen M, Wang ZF Prox1 transcription factor as a marker for vascular tumorsevaluation of 314 vascular endothelial and 1086 nonvascular tumors. Am J Surg Pathol. 2012 Mar;36(3):351-9 


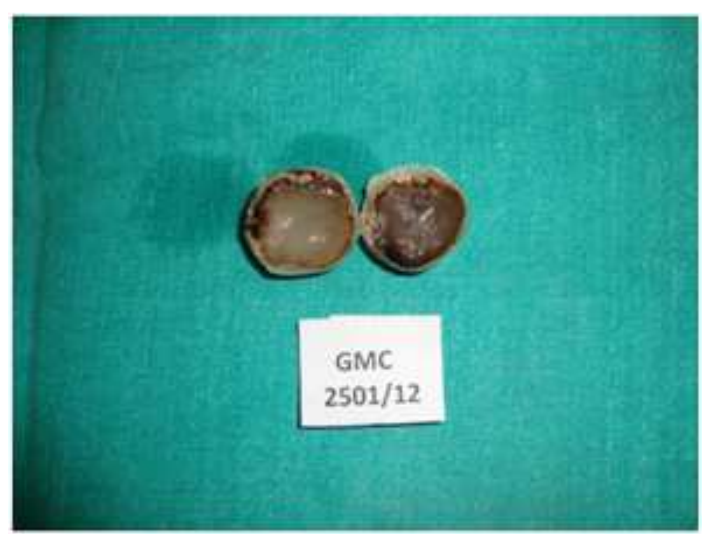

Fig - 1

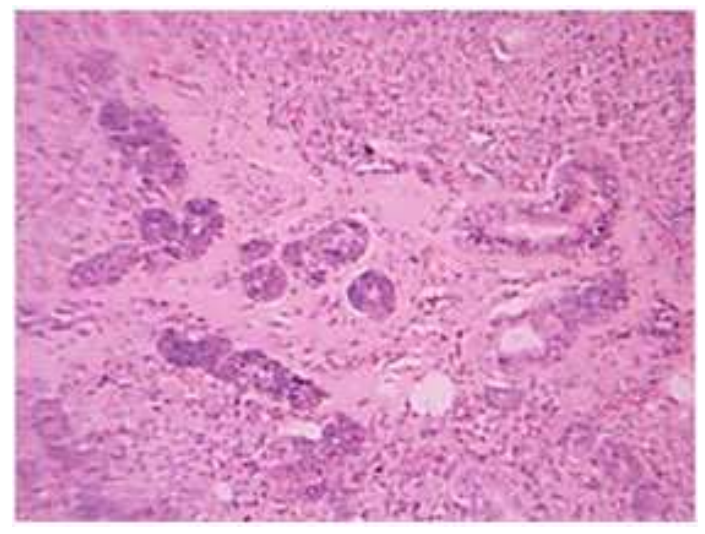

Fig - 3
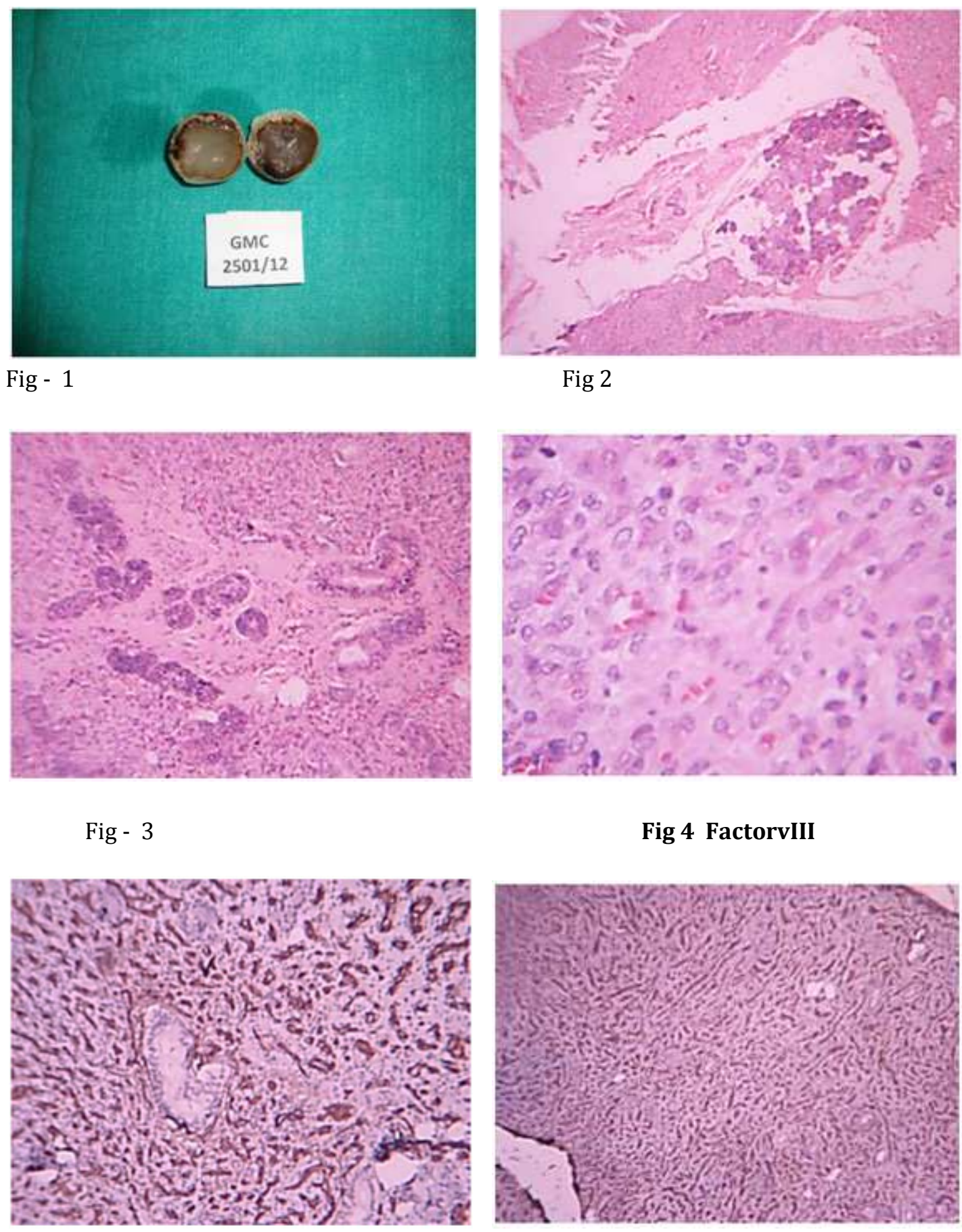

Fig 2

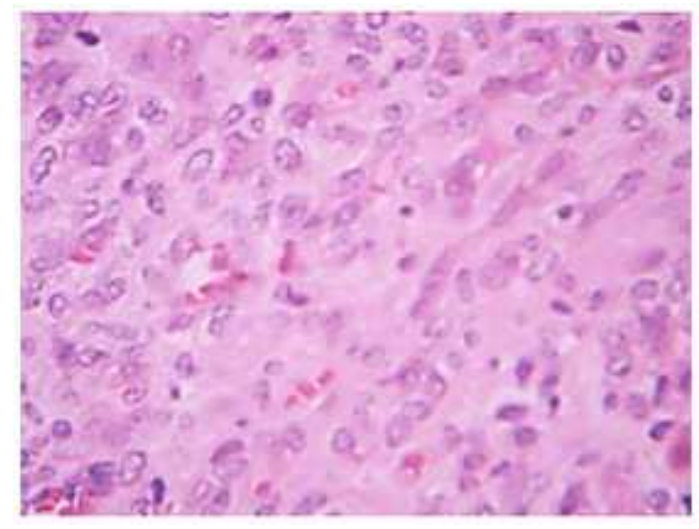

Fig 4 FactorvIII

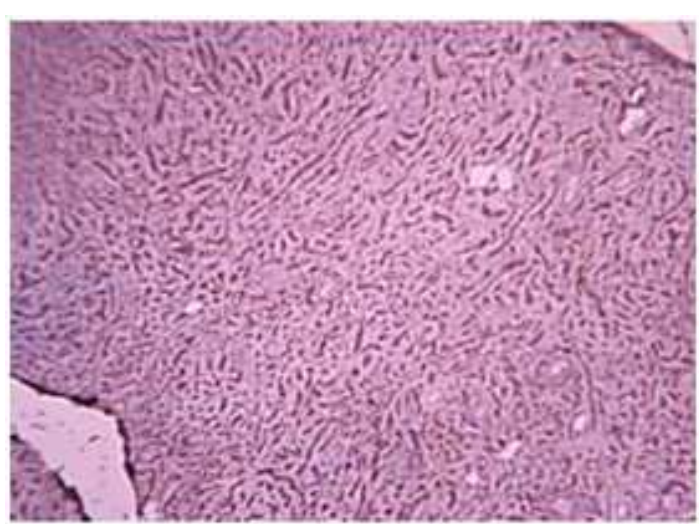

Fig 5 Immunohistochemistry: The tumor showed strong positivity for CD34 and Factor VIII antigen.The entrapped glands remained unstained. 